\title{
A Lagrangian Decomposition Model for Unit Commitment Problem
}

\author{
S. Maheswari \\ Department of Mathematics \\ Sathyabama University \\ Chennai - 119
}

\author{
C. Vijayalakshmi \\ Department of Mathematics \\ Sathyabama University \\ Chennai - 119
}

\begin{abstract}
This paper designs an optimization model for Unit Commitment Problem (UCP) which is formulated as a Non Linear Programming Problem (NLPP) with respect to various constraints. The model can be solved by Lagrangian Decomposition (LD) problem and it is obtained by relaxing the constraints from NLPP using Lagrangian Relaxation Method. Generation scheduling is used to find the maximum demand utilized in the planning horizon by the minimum generation cost. It reveals the fact that Maximum profit can be achieved for power generating utility in order to supply the load in a reliable manner. Based on the numerical calculations and graphical representations, the optimum value is obtained by the proposed model for electrical power system cycles.
\end{abstract}

\section{Keywords}

Unit commitment, Generation Scheduling, Lagrangian Decomposition model, Generation Cost.

\section{INTRODUCTION}

In recent years, power demand has been increased because of raising population. So the electrical engineers are planning for efficient power utilization, operation and scheduling of generation in the power system. Any system whose supplying services to a large population experience as cycles. For example transportation system, communication system and electrical power system. Particularly in electrical power system, the use of electric power has a cycle. The total load on the system will generally be higher during day time and early evening when industrial loads are high; lights are on and lower during the late evening and early morning when most of the population is asleep. The problem is in the operation of an electric power system. That is to generate the units when the units are "turn it on" and "turn it off". Generating unit is to "turn it on" which is defined as "commit". Simply "commit" enough units to cover the maximum system load. Allen et.al. (1984) have discussed the unit commitment problem in power generation operation and control.

The Unit Commitment Problem (UCP) gives the optimization of the generation of the units, how the money can be saved by turning units off (decommitment them) when they are not needed. Schedule the generation units in order to serve the load (demand) at the minimum operating cost while meeting all plant and system constraints. F.N. Lee (1989) has designed a fuel constrained unit commitment method.

Generation scheduling involves the determination of startup and the generation levels for each unit over a given scheduling period.

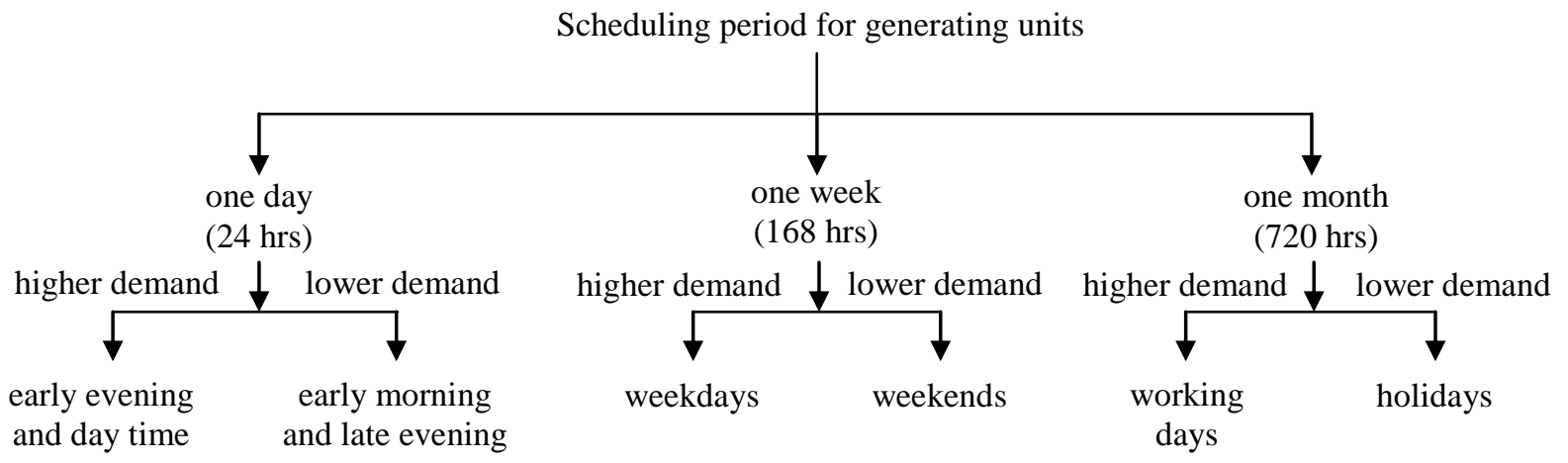

S. Viramani et.al. (1989) have discussed the implementation of a Lagraginan relaxation based unit commitment problems. Rudolf et.al. (1989) has designed a genetic algorithm for solving the unit commitment problem of a hydro thermal power system. Lagrangian framework is a successful method as discussed by A. Cohen et al. (1987), J.J. Shaw et al. (1985), L.A.F.M. Fesseira et al. (1989), A. Renaud (1993), S. Maheswari et al.(2011,2012) and S.J. Wang et al. (1995).

In this paper, the Lagrangian multipliers are used in the objective of LD model which leads to the faster convergence.
These were added in the objective function as a penalty function which are determine the optimal solution of NLPP with respect to various system operating conditions.

\section{OPTIMIZATION MODEL}

The objective of this model is to generate the $\mathrm{k}$ units that would satisfy the expected demand and to give the minimum power generation cost in the planning time interval.

\subsection{System Parameters}

$\mathrm{Z} \quad-$ Total generation cost of the generation units

$B_{j} \quad-\quad$ The cost associated with the build of generation 
Units

$M_{j}(P)$ - Maintenance cost for generation of units

$\mathrm{CF}_{\mathrm{j}}(\mathrm{P})$ - Power production cost (based on fuel consumed)

$\mathrm{S}_{\mathrm{j}} \quad-\quad$ Startup cost, thermal units which depends on Prevailing temperature of the boilers

$\ell(\mathrm{t}) \quad-\quad$ Power generated must be equal to the demand (Load) at time' $t$ '

$\mathrm{T}_{\mathrm{j}}(\mathrm{P}) \quad-\quad$ Transportation cost for the generation of units

$\mathrm{IC}_{\mathrm{j}} \quad-\quad$ The cost is related to the interest on working Capital

$\mathrm{IV}_{\mathrm{j}} \quad-\quad$ The cost is return on investment

$\mathrm{L}_{\mathrm{j}} \quad-$ Labour cost

$\mathrm{TS}_{\mathrm{j}} \quad-$ Transmission cost

$\mathrm{T} \ell_{\mathrm{j}} \quad-\quad$ Transmission loss cost

\subsection{Decision Variables}

$\mathrm{P}_{\mathrm{j}}(\mathrm{t}) \quad$ : Amount of power produced by unit $\mathrm{j}$ at time ' $\mathrm{t}$ '

$v_{j}(t) \quad$ : Control variable of unit $j$ at time ' $t$ '

$$
v_{j}(t)=\left\{\begin{array}{l}
0 \text { if unitjisoff at time ' } t ' \\
1 \text { if unit jis on at time ' } t '
\end{array}\right.
$$

$x_{j}(t) \quad: x_{j}(t)=\left\{\begin{array}{l}0 \text { if } x \text { is false } \\ 1 \text { if } x \text { is true }\end{array}\right.$

$S_{j}\left[x_{j}(t)\right]: S_{j}\left[x_{j}(t)\right]= \begin{cases}S_{c} & \text { if } x_{j}(t) \leq t_{\text {coldstart }} \\ S_{h} & \text { otherwise }\end{cases}$

Where $S_{c}$ - cold startup cost which applies for the thermal

Unit has been off for a long period

$\mathrm{S}_{\mathrm{h}}-$ hot startup cost which applies for the unit recently turned off

$\mathrm{P}_{\mathrm{j}}^{\min } \quad$ : Minimum power that can be generated by unit $\mathrm{j}$

(MW)

$\mathrm{P}_{\mathrm{j}}^{\max } \quad$ : Maximum power that can be produced by unit $\mathrm{j}$

(MW)

An optimal commitment schedule, there are two decision variables. The first variable $\left[\mathrm{P}_{\mathrm{j}}(\mathrm{t})\right]$ denotes the amount of power to be generated and the second is control variable $\left[\mathrm{v}_{\mathrm{j}}(\mathrm{t})\right]$ whose value is 1 if the generating unit $\mathrm{j}$ is committed at hour ' $t$ ' and 0 otherwise. The cost of the power produced by the generating unit $\mathrm{j}$ depends on the amount of fuel consumed.

The objective is to minimize the cost of the power produced by generation units.

\subsection{Objective Function:}

$\mathrm{Z}=\operatorname{Min} \sum_{\mathrm{t}=1}^{\mathrm{T}} \sum_{\mathrm{j}=1}^{\mathrm{K}}\left[\mathrm{CF}_{\mathrm{j}}+\mathrm{S}_{\mathrm{j}}\right] \times \mathrm{P}_{\mathrm{j}}(\mathrm{t})$

$$
+\sum_{\mathrm{t}=1}^{\mathrm{T}} \sum_{\mathrm{j}=1}^{\mathrm{K}}\left[\mathrm{M}_{\mathrm{j}}+\mathrm{T} l_{\mathrm{j}}+\mathrm{IC}_{\mathrm{j}}+\mathrm{IV}_{\mathrm{j}}\right]+\left[\mathrm{CF}_{\mathrm{j}} \times \mathrm{P}_{\mathrm{j}}(\mathrm{t})\right]
$$

Subject to the constraints,

$\sum_{j=1}^{K} v_{j}(t) P_{j}(t)=l(t), t=1,2, \ldots, T$

$v_{j}(t) P_{j}^{\min } \leq P_{j}(t) \leq v_{j}(t) P_{j}^{\max }$

$\mathrm{v}_{\mathrm{j}}(\mathrm{t})=1 \sum_{\mathrm{t}=\mathrm{t}_{\mathrm{s}}}^{\mathrm{t}-1} \mathrm{v}_{\mathrm{j}}(\mathrm{t}) \geq$ minuptime $\mathrm{j}$

$v_{j}(t)=0 \quad \sum_{t=t_{d}}^{t-1}\left[1-v_{j}(t)\right] \geq$ mindown time $j$

$\sum_{j=1}^{K} M_{j} \times P_{j}(t) v_{j}(t)=l(t), t=1,2, \ldots, T$

$\sum_{\mathrm{j}=1}^{\mathrm{K}} \mathrm{T}_{\mathrm{j}} \mathrm{P}_{\mathrm{j}}(\mathrm{t}) \mathrm{v}_{\mathrm{j}}(\mathrm{t})=l(\mathrm{t}), \mathrm{t}=1,2, \ldots, \mathrm{T}$

$\sum_{j=1}^{K} B_{j} P_{j}(t) v_{j}(t)=l(t), t=1,2, \ldots, T$

$\sum_{j=1}^{K} L_{j} P_{j}(t) v_{j}(t)=l(t), t=1,2, \ldots, T$

$\sum_{\mathrm{j}=1}^{\mathrm{K}} \mathrm{TS}_{\mathrm{j}} \mathrm{P}_{\mathrm{j}}(\mathrm{t}) \mathrm{v}_{\mathrm{j}}(\mathrm{t})=l(\mathrm{t}), \mathrm{t}=1,2, \ldots, \mathrm{T}$

$\sum_{j=1}^{\mathrm{K}} \mathrm{T} \ell_{\mathrm{j}} \mathrm{P}_{\mathrm{j}}(\mathrm{t}) \mathrm{v}_{\mathrm{j}}(\mathrm{t})=l(\mathrm{t}), \mathrm{t}=1,2, \ldots, \mathrm{T}$

$\sum_{j=1}^{K} \operatorname{IV}_{j} P_{j}(t) v_{j}(t)=l(t), t=1,2, \ldots, T$

\section{LAGRANGIAN DECOMPOSITION} MODEL

The objective of LD model is obtained by relaxing the constraints from NLPP using Lagrangian Relaxation Method. It gives minimum generation cost of the electrical power system.

Relaxing the equation (1)

\subsection{Lagrangian Function}

$$
\begin{aligned}
L\left[Z, \mu_{P_{j}}\right]=\operatorname{Min} & \left\{\left(\sum_{t=1}^{T} \sum_{j=1}^{K}\left[C F_{j}+S_{j}\right] \times P_{j}(t)\right.\right. \\
+ & \left.\sum_{t=1}^{T} \sum_{j=1}^{K}\left[M_{j}+T l_{j}+\mathrm{IC}_{j}+\mathrm{IV}_{j}\right]+\left[\mathrm{CF}_{\mathrm{j}} \times \mathrm{P}_{\mathrm{j}}(\mathrm{t})\right]\right) \\
& \left.+\mu_{\mathrm{P}_{\mathrm{j}}}\left(\sum_{\mathrm{j}=1}^{\mathrm{K}} \mathrm{v}_{\mathrm{j}}(\mathrm{t}) \mathrm{P}_{\mathrm{j}}(\mathrm{t})-l(\mathrm{t})\right)\right\}
\end{aligned}
$$


Subject to

$v_{j}(t) P_{j}^{\min } \leq P_{j}(t) \leq v_{j}(t) P_{j}^{\max }$

$v_{j}(t)=1 \sum_{t=t_{s}}^{t-1} v_{j}(t) \geq$ minuptime $j$

$v_{j}(t)=0 \quad \sum_{t=t_{d}}^{t-1}\left[1-v_{j}(t)\right] \geq$ mindown time $j$

$\sum_{j=1}^{K} M_{j} \times P_{j}(t) v_{j}(t)=l(t), t=1,2, \ldots, T$

$\sum_{j=1}^{K} T_{j} P_{j}(t) v_{j}(t)=l(t), t=1,2, \ldots, T$

$\sum_{j=1}^{K} B_{j} P_{j}(t) v_{j}(t)=l(t), t=1,2, \ldots, T$

$\sum_{j=1}^{K} L_{j} P_{j}(t) v_{j}(t)=l(t), t=1,2, \ldots, T$

$\sum_{j=1}^{K} T S_{j} P_{j}(t) v_{j}(t)=l(t), t=1,2, \ldots, T$

$\sum_{\mathrm{j}=1}^{\mathrm{K}} \mathrm{T} \ell_{\mathrm{j}} \mathrm{P}_{\mathrm{j}}(\mathrm{t}) \mathrm{v}_{\mathrm{j}}(\mathrm{t})=l(\mathrm{t}), \mathrm{t}=1,2, \ldots, \mathrm{T}$

$\sum_{j=1}^{K} \operatorname{IV}_{j} P_{j}(t) v_{j}(t)=l(t), t=1,2, \ldots, T$

Here $\mu_{\mathrm{Pj}}$ is a penalty function with respect to the power factor

\subsection{Lagrangian Relaxation Method}

Lagrangian relaxation replaces the original problem with an associated Lagrangian problem whose optimal solution will provide a bound on the objective function of the original problem. This is achieved by eliminating (i.e., relaxing one or more) of the constraints of the original model and adding these constraints, multiplied by an associated Lagrange multiplier, to the objective function. The main objective is to relax constraints that will result in a relaxed problem that given values of the multipliers, is much easier to solve optimally. The role of these multipliers is to drive the Lagrangian problem toward a solution that satisfies the relaxed constraints.

The Lagrangian relaxation approach replaces the problem of identifying the optimal values of all of the decision variables with one of finding optimal or good values for the Lagrangian multipliers. Most Lagrangian-based heuristics use a search heuristic to identify the optimal multipliers. A major benefit of Lagrangian-based heuristics is that they generate bounds (i.e., lower bounds on minimization problems and upper bounds on maximization problems) on the value of the optimal solution of the original problem. For any set of values for the Lagrangian multipliers, the solution to the Lagrangian model is less than or equal to the solution to the original model.

The solution to the Lagrangian problem for any given values of the Lagrangian multipliers will generally violate one or more of the relaxed constraints. Many Lagrangian based algorithms incorporate additional heuristics to convert these infeasible solutions to feasible ones. In this way, the researchers can produce good solutions to the original model. The best feasible solution among those found by the procedure at any point represents the upper bound on the value of the true optimal solution. The difference between the upper and lower bounds is referred to as the "gap". If the gap reaches zero (or some minimum value based on the integer properties of the model) then it should be found the optimal solution. Otherwise, when the gap gets sufficiently small (e.g. less than 1\%), the analyst may stop the procedure and be satisfied that the current best solution is within $1 \%$ of optimality.

An excellent tutorial on the general application of Lagrangian relaxation can be found in Fisher (1985). An exposition of its use in location models is in the text by Daskin (1995).

In this paper, the optimal solution of NLPP is obtained by Lagrangian Decomposition Model with respect to the power factor which satisfies the load in the power system.

\section{NUMERICAL CALCULATIONS AND GRAPHICAL REPRESENTATIONS}

Generation Scheduling gives the cycles for generation of units. The optimal value of LD is obtained by the algorithmic approach which is implemented in MATLAB 7.0. Computations were performed on an acer pc. The testing data sets are summarized in table.1.

Based on numerical calculations and graphical representations, the minimum power generation cost Rs. 38513 lakhs is obtained in the month August while the planning schedule period is April to August. Generation Scheduling gives the minimum production cost over a time interval which satisfies the demand and operating constraints of power system cycles. That is, it gives maximum power utility in the planning horizon which meets out all the demand. If the generation scheduling period is one day, then the computation is easy. Complication is in the computation of one week and one month period. 
Table 1. Optimum Generation Cost

\begin{tabular}{|c|c|c|c|c|c|c|c|c|c|c|c|}
\hline $\begin{array}{l}\text { Period } \\
\text { T (hrs) }\end{array}$ & $\begin{array}{r}\text { Units } \\
(\mathbf{K})\end{array}$ & $\begin{array}{c}\begin{array}{c}\text { Cost } \\
\text { function }\end{array} \\
\mathbf{C F}_{\mathbf{j}} \\
\text { (units) }\end{array}$ & $\begin{array}{c}\begin{array}{c}\text { Start up } \\
\text { cost }\end{array} \\
\mathrm{S}_{\mathrm{j}} \\
\text { (units) }\end{array}$ & $\begin{array}{l}\text { Power } \\
\text { Function } \\
\text { (million } \\
\text { units) }\end{array}$ & $\begin{array}{c}\text { Variable } \\
\text { cost } \\
\text { (lakhs) }\end{array}$ & $\begin{array}{c}\text { Maintenance } \\
\qquad \mathbf{M}_{\mathbf{j}} \\
\text { (lakhs) }\end{array}$ & $\begin{array}{c}\text { Depreciation } \\
\mathrm{T \ell}_{\mathrm{j}} \\
\text { (lakhs) }\end{array}$ & $\begin{array}{c}\text { Return } \\
\text { on } \\
\text { investment } \\
\mathbf{I V}_{\mathbf{j}} \\
\text { (lakhs) }\end{array}$ & $\begin{array}{c}\text { Interest } \\
\text { on } \\
\text { capital } \\
\mathrm{IC}_{\mathrm{j}} \\
\text { (lakhs) }\end{array}$ & $\begin{array}{l}\text { Fixed } \\
\text { Cost } \\
\text { (lakhs) }\end{array}$ & $\begin{array}{l}\text { Total } \\
\text { cost } \\
\text { (lakhs) }\end{array}$ \\
\hline May & 17 & 217 & 76 & 1475.131 & 31909.68 & 4356.68 & 2990.81 & 3413.12 & 485.61 & 11246.22 & 43155.90 \\
\hline June & 17 & 210 & 67 & 1662.957 & 34886.74 & 4350.12 & 2990.81 & 3413.12 & 484.59 & 11238.64 & 46125.38 \\
\hline July & 17 & 196 & 66 & 1722.533 & 33838.96 & 4415.53 & 2990.81 & 3413.12 & 467.44 & 11286.90 & 45125.86 \\
\hline
\end{tabular}

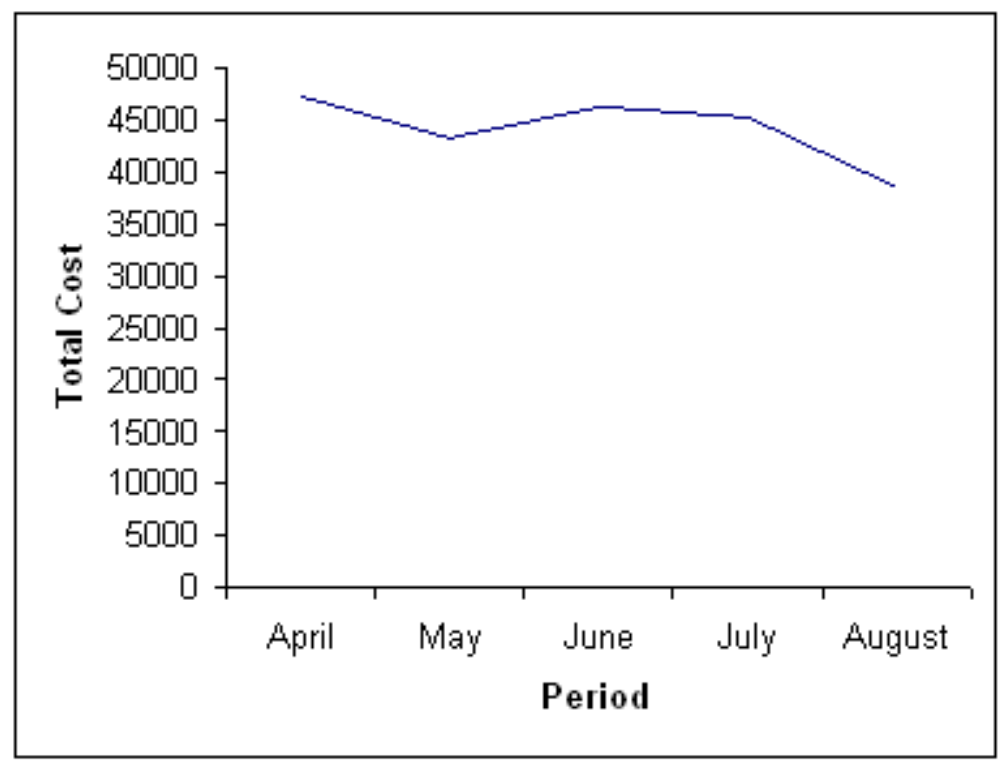

Figure 1. Optimization Graph

\section{CONCLUSION}

In this paper, the model is designed for Unit Commitment problem which is formulated as Non Linear Programming Problem and then decomposed by Lagrangian Relaxation Method. Lagrangian Decomposition model gives minimum generation cost for the generating thermal units over a time interval. That is, the maximum power utilized in the planning period. Based on the numerical calculations and graphical representation, the optimum value of NLPP is achieved from Lagrangian Decomposition model with respect the generation scheduling of an electric power system. It leads to the effective power utility in the planning horizon.

\section{ACKNOWLEDGMENTS}

The authors would like to thank Er. R. Santhosh Kumar, A.E, TNEB, Chennai, India, for his valuable support and guidance during the research of this paper.

\section{REFERENCES}

[1] Allen J. Wood, Bruce F. Wollenbrg, "Power generation operation and control", John Wiley \& Sons, New York, 1984.

[2] Rudolf, R. Bayrleithner, “A genetic algorithm for solving the unit commitment problem of a hydro thermal power system", IEEE transactions on power systems, Vol. 14, No. 4, Nov. 1999, pp. 1460-1468.

[3] C.L. Wadhwa, "Electrical Power Systems", Third Edition, New Delhi, 2003.

[4] F.N. Lee, "A Fuel-Constrained Unit Commitment Method", IEEE Transaction on Power Systems, August 1989, pp. 691-698.

[5] F. Zhuang, F.D. Galiana, "Towards A More Rigorous and Practical Unit Commitment by Lagrangian Relaxation", IEEE Trans. On Power Systems, Vol. PWRS, pp. 763-770, May 1988. 
[6] S. Virmani, Cadrin, K. Imhof, S. Mukherjee, "Implementation of a Lagrangian Relaxation Based Unit Commitment Problems, IEEE Transaction on Power Systems, Vol. 4, No.4, October 1989, pp. 692-698.

[7] S. Maheswari and C. Vijayalakshmi, "An Optimal Design to Schedule the Hydro power Generation using Lagrangian Relaxation Method", Proceedings of the International Conference on Information Systems Design and Intelligent Applications 2012 (INDIA 2012) Computer Society of India, Visakhapatnam, ISBN : 9783-642-27442-8, AISC 132, pp.723-730, Springer-Verlag Berlin Heidelberg 2012.

[8] A. Cohen and V. Sherkat, "Optimization-Based Methods for Operations Scheduling", Proceedings of IEEE, Vol. 75, No. 12, 1987, pp. 1574-1591.

[9] J.J. Shaw and D. P. Bertsekas, "Optimal Scheduling of Large Hydrothermal Power Systems", IEEE Transactions on Power Apparatus and Systems, Vol. PAS-104, 1985, pp. 286-293.

[10] L.A.F.M. Ferreira, T. Anderson, C.F. Imparato, T.E. Miller, C.K. Pang, A. Svoboda, A.F. Vojdani, "Short-
Term Resource Scheduling in Multi-Area Hydrothermal Power Systems", Electric Power \& Energy Systems, Vol. 11, No. 3, 1989, pp. 200-212.

[11] A. Renaud, "Daily Generation Management at Electricite de France: From Planning Towards Real Time", IEEE Transaction on Automatic Control, Vol. 38, No. 7, 1993, pp. 1080-1093.

[12] S. Maheswari and C. Vijayalakshmi, "Optimization Model for Electricity Distribution System Control using Communication System by Lagrangian Relaxation Technique", CiiT International Journal of Wireless Communication, Print: ISSN 0974 - 9756 \& Online: ISSN 0974 - 9640, Vol 3, No 3, pp. 183-187, March 2011.

[13] S.J. Wang, S.M. Shahidehpour, D.S. Kirschen, S. Mokhtari, and G.D. Irisarri, "Short-Term Generation Scheduling with Transmission Constraints Using Augmented Lagrangian Relaxation", IEEE Transactions on Power Systems, Vol. 10, No. 3, Aug. 1995, pp. 1294-1301. 